УДК 340.115

DOI: $10.14451 / 2.130 .18$

\title{
ПОНЯТИЕ ДИСФУНКЦИИ КАК ИНСТРУМЕНТ ФУНКЦИОНАЛЬНОГО АНАЛИЗА ПРАВА
}

\author{
(c) 2019 Зяблова Татьяна Евгеньевна \\ кандидат юридических наук, доцент \\ доцент кафедры теории и истории государства и права факультета права и управления \\ Владимирский юридический институт ФСИН России, Россия, Владимир \\ E-mail: tizet69@mail.ru
}

\section{(C) 2019 Комарова Яна Бахрузовна}

преподаватель кафедры теории и истории государства и права факультета права и управления Владимирский юридический институт ФСИН России, Россия, Владимир

E -mail: Ya. Ireland@mail.ru

\section{(c) 2019 Мамчун Владимир Вячеславович}

кандидат юридических наук, доцент; доцент кафедры «Теория и история государства и права»

Юридического института им. М.М. Сперанского

Владимирский государственный университет им А.Г. и Н.Г. Столетовых, Россия, Владимир

E-mail: vladimir_mamchun@mail.ru

В статье рассматриваются возможности использования понятия дисфункции в функциональных исследованиях права. На основе анализа опыта изучения права посредством социологического понятия дисфункции делается вывод о нецелесообразности практики социологической интерпретации дисфункции права. Обосновывается возможность и необходимость разработки понятия дисфункции права как юридического понятия, адаптированного к предметно-методологической специфике и понятийным рядам теории права. Рассматриваются перспективы его дальнейшего использования в процессах познания и создания права.

Ключевые слова: общая теория права, право, правовая дисфункция, функция права, дисфункция права, теория права, функционирование права, последствия функционирования права, социологический функционализм, функциональный анализ права.

Динамика научного познания порождает новые разнообразные комбинации методов научного познания и используемых в сочетании с ними познавательных средств и диктует необходимость поиска новых. Применительно к теории функций права, давно и продуктивно оперирующей понятием функции, таким новым гносеологическим инструментом является понятие дисфункции. Потенциально оно способно не только дополнить имеющиеся научные представления о функциях, но и объяснить факт существования иного, нефункционального воздействия, которое не «укладывается» в понятие функции права. Исследование дисфункции позволит раскрыть природу и детерминацию такого воздействия с тем, чтобы разработать надежные и эффективные средства для его предотвращения, а в случае невозможности полного исключения из процессов функционирования права - его локализации и минимизации.
В исследованиях проводимых в рамках теории функций права, дисфункция удостаивалась лишь фрагментарного упоминания о ее существовании или указания на ее связь с негативным влиянием права на регулируемые отношения [15, с. 11-12; 5, с. 72, 208; 4, с. 18; 11; 12]. Первый опыт специальных исследований дисфункций права представлен единичными работами [3; $13 ; 7 ; 6 ; 2]$. Немногочисленность работ в теории права, посвященных исследованию дисфункций права с одной стороны, и их преимущественная ориентация на социологическое понимание дисфункции - с другой, не позволяет констатировать удовлетворительность состояния разработанности проблемы. Этим обстоятельством предопределяется цель настоящей работы, которой является изучение возможностей использования понятия дисфункции в функциональном анализе права. Для ее достижения необходимым видится анализ практики использования социо- 
логического понятия дисфункция для изучения права в теории права, определение принципиальной возможности использования понятия дисфункции в функциональном анализе в рамках общей теории права, оценка дальнейших перспектив функционального анализа посредством понятия дисфункции права.

Отношение к дисфункции права в общей теории права обусловлено тем, что задачей юридической науки является познание, прежде всего, позитивного потенциала права, который связывается именно с функциями. Это, собственно, и привело понятие дисфункции, на периферию исследовательского внимания. Нарастание кризисных явлений в обществе и в самом праве в 90-е, в начале 2000-х гг., заставило заново переосмысливать его роль и значение в обществе, однако уже с противоположных позиций, в контексте уже нефункционального воздействия на общественные отношения. Именно для этого и было востребовано понятие дисфункции, разработанное в западной социологии, где под функциями понимаются наблюдаемые последствия, способствующие адаптации или приспособлению данной системы; а под дисфункциями те, которые уменьшают адаптацию или регулировку системы [10, с. 145].

В таком, социологическом понимании понятие дисфункции и применено для анализа права. Результаты этой исследовательской практики достаточно неоднозначны. Понимание того, что понятие дисфункции в используемом виде не «вписывается» в понятийный аппарат теории права, подвигло автора концепции правовой дисфункции М.А. Дамирли, к отказу от использования термина «дисфункция права» [3, с. 14]. Правовая дисфункция позиционирована им в качестве основы стратегии познания права как альтернативы традиционной (основывающейся, очевидно, на понятии функции). При этом, акцентируется, что традиционная стратегия изучает право с точки зрения должного, в то время как предлагаемая - с точки зрения сущего [3, c. 14].

Думается, едва ли это можно рассматривать в качестве достаточного аргумента в пользу использования социологического понятия. Тот факт, что функция права в теории права изучается, прежде всего, с точки зрения должного, вовсе не означает, что в сферу исследовательского внимания не включается и сущее, реальное состояние права, процессы и результаты его воздействия на регулируемые отношения. Подтверждением этому служат понятия функционирования $[1$, с. 169,190$]$ и эффективности функции права [14, с. 81], которыми активно оперирует теория функций права. Относительно результатов функционирования права, следует отметить, что они действительно не включаются в функциональный юридический анализ, так как «лежат за пределами понятия функции, которое включает только то, что непосредственно характеризует функцию права, отражает исключительно ее специфику» $[14$, с. 81], и в теории права описываются другими понятиями, например, «состояние законности», «правопорядок», «правовое поведение» и пр.

Утверждается, что правовая дисфункция подразумевает нарушение «не просто норм права, а нарушение в функционировании права, такое его состояние, когда оно не может реализовывать свое социальное назначение, свои функции и роль» [3, с. 14]. Одновременно она рассматривается как «правовая функция со знаком минус» [3, с. 14] и как «отсутствие определенных качественных характеристик в социальноправовой жизни общества, в правопорядке в частности, выявляемое через измерение нарушений в функционировании права, когда право не может полностью или частично реализовывать свое социальное назначение, свои функции и роль в социальной системе» [3, с. 15].

Функционирование права связывается с процессом реализации функций. Поэтому право не может одновременно и функционировать (реализовывать свои функции) и не реализовывать функции (т.е. не функционировать). Если все же процесс функционирования возникает, то право все же в состоянии реализовывать свои функции. Другое дело, что результаты функционирования по определенным основаниям могут не удовлетворять потребности общества и служить индикатором эффективности функции.

Трудно признать верным суждение о возможности существования состояния, когда право не может реализовывать свое социальное назначение, свои функции и роль. Это не просто «нарушение в функционировании», а утрата функциональности. Такое возможно только тогда когда право не функционирует, так как «правовая дисфункция» в этой логике, функцией не является. Такое возможно только в случае утраты правом качества социального нормативного регулятора, что равнозначно «смерти» права. 
Это отвергает один из видных представителей социологического функционализма Р. Мертон: «Напряжения, накапливающиеся в социальной структуре в результате дисфункции последствия существующих элементов, не ограничены жесткими рамками соответствующего социального планирования и со временем приведут к институциональному развалу и глубоким социальным изменениям. Когда эти изменения превышают определенный, но нелегко определяемый уровень, принято говорить, что появилась новая социальная система» [9, с. 133].

Другими словами, факт существования дисфункций права не приводит к его исчезновению с исторической арены, а при накоплении их критического объема, влечет замену одного права другим, например, в рамках смены исторических типов. Однако и в этом случае право не утрачивает способности реализовывать свое социальное предназначение. Свидетельством этого является сам факт социального и правового прогресса.

Наконец, главный вопрос, что именно описывает понятие правовой дисфункции: само право, процесс его функционирования, результаты, или состояние общества? Может ли оно в этом виде быть инструментом познания права?

Очевидно, что наделение термина «правовая дисфункция» способностью отражать столь широкий спектр значений, сводит ее по существу к понятию, описывающего все негативное, что так или иначе связано с правом и одновременно претендует на придание ей статуса широкой правовой категории. Возникает вопрос о целесообразности введения такой категории в теорию права, так как с этим вполне справляются и сами понятия, которые «втискиваются» в ее состав. Кроме того, возникает вопрос об обоснованности использования самого термина «правовая дисфункция», так как если это дисфункция, то дисфункция чего?

Постановка вопроса об «отсутствии определенных качественных характеристик в социально-правовой жизни общества» говорит о том, что само общество и выступает носителем дисфункции. Но если это так, то почему она дисфункция правовая, ведь речь идет о социальноправовой жизни, понятие которой шире не только понятия права и правовой системы общества, но и понятия правовой жизни [8, с. 54]. Ее состояние детерминировано не только правом, но и иными социальными регуляторами. Кроме того, она обусловлена также факторами, природа которых не связана с правом. В связи с этим непонятно, как именно с помощью чего можно «измерить» нарушения в функционировании права?

Под влиянием социологического функционализма предпринимаются попытки не только «внедрить» в теорию права социологическое понятие дисфункции, но и модернизировать понятие самой функции права. Как пишет С.В. Бирюков, функции права «логичнее соотносить с основными направлениями воздействия (влияния) права (как норм, так и принципов правосознания и сложившихся правовых отношений) на всю окружающую его среду, включая неправовые общественные отношения» [2, с. 1054]. В этом случае не только понятие правовой дисфункции, но и функции права, приобретает способность описывать все то, что происходит и с самим правом, и с правовым регулированием, и с состоянием регулируемых общественных отношений, в том числе, и то, что и не связано с правом.

Определенный интерес представляют и аргументы сторонников социологической интерпретации функций и дисфункций права в пользу отказа понятия, разработанного теорией права. К обоснованию необходимости отказа от классического понимания функций права и перехода к социологической методологии в исследованиях, приводятся аргументы филологического порядка. Так, в частности, отмечается что «ни в одной другой отрасли науки, кроме юриспруденции, термин «функция» не применяется для обозначения основного направления действия чего-либо. Более того, этимология и семантика слова «функция» не предполагают возможность понимания функций права в качестве основных направлений его действия» [7, с. 79].

Трудно признать такую аргументацию убедительной. При формировании юридического термина, в том числе и научного, приоритетностью обладает не соответствие нормам литературного языка, а способность отразить стоящее за понятием, которое обозначает тот или иной термин, правовое явление, процесс, их стороны, свойства и пр. Именно это имеет первостепенное значение для решения практических вопросов создания, реализации и познания права, что впрочем, не следует рассматривать как апологию или требование игнорирования норм русского литературного языка при создании научных терминов. 
В рамках социолого-филологического понимания функция права (гражданского общества) рассматривается «в качестве выполняемой им роли, удовлетворяющей потребности общества, социальных групп и индивидов» [7, с. 79]. Дисфункция права, рассматриваемая с этих позиций, понимается как некорректность осуществления функций права, влекущая негативные функционирования [7, с. 80].

Постановка вопроса о функции права как o «роли, удовлетворяющей потребности общества», влечет необходимость следующего уточнения: потребности общества удовлетворяет не роль, а само право, а то обстоятельство что право обладает такой способностью и обусловливает его роль в обществе, выраженную в функции. Между тем, постулат о том, что активная роль выражается в его функциях [1, с. 191] является исходным моментом понимания функции права в общей теории права. Связь функции права и его роли не отрицается, а напротив, подчеркивается. «Понятие «функция права»,- пишет Т.Н. Радько,- выражает основные направления воздействия права, характеризуя ту или иную его социальную роль (курсив наш - Т.З., Я.К., В.М.), выполнение им определенных задач в соответствии с социальным назначением» [14, с. 77]. Акцентирование внимания в понимании функции права только лишь на роли при игнорировании того, что функция права не только проявляется вовне, но и имманентна праву, переводит ее изучение в сферу социологии. Трактовка дисфункции права как последствий реализации функций ведет к замене анализа права анализом социальных последствий его воздействия, пусть даже описываемых в юридических терминах и приводит к констатации определённых социальных фактов, в основной массе уже известных юридической науке и изучаемых посредством существующих правовых понятий. Это создает риск подмены юридического функционального анализа социологическим.

Как видно, при любом варианте социологической интерпретации понятия дисфункции, независимо от того, называть ее правовой дисфункцией или непосредственно дисфункцией права, оно рассматривается не как соотносимое с понятием функции права и характеризует собственно, не само право, а состояние общественных отношений, которое в реальности детерминируется целым комплексом различных факторов. Использование социологически интерпретированного понятия дисфункции для констатации такого состояния не позволяет вычленить результат негативного действия самого права, отделить его от результата действия других (нефункциональных) факторов. И, пожалуй, самым главным недостатком такой практики видится то, что акцентируя внимания на обществе, на фактах негативного влияния права на общественные отношения, констатируя «отсутствие определенных качественных характеристик в социально-правовой жизни общества», она не способна объяснить и описать то, что именно в праве порождает саму возможность их существования. Указание на политические, экономические и иные причины, нестабильность, дефектность, казуистичность законов и др. [3, c. 15], иллюстрирует, но не объясняет, почему право дисфункционально, что именно в нем составляет источник такой активности.

Таким образом, практика социологической интерпретации дисфункции права ставит больше вопросов, чем дает ответов. Вместе с тем, ценность ее состоит в том, что она наглядно доказывает, что нельзя просто взять социологическое понятие дисфункции и механически «пересадить» на правовую почву. Это влечет конкуренцию с уже другими понятиями теории права, переносит фокус исследовательского внимания с права на общество и не дает сколько-нибудь ощутимого прироста научного знания о самом праве.

В целом, опыт исследования права посредством социологически интерпретированного понятия дисфункции не подтверждает целесообразность его использования в юридических исследованиях в таком виде. В данном случае новизна термина не сопровождается содержательной новизной результатов, так как они описываются (могут быть описаны) в понятиях разработанных теорией права и успешно применяемых ею для анализа процессов и результатов воздействия права на регулируемые общественные отношения.

Это, свою очередь, ставит вопрос о принципиальной возможности применения понятия дисфункции для изучения права. На него следует ответить утвердительно и именно практика социологических интерпретаций дисфункций свидетельствует в пользу необходимости разработки дисфункции права именно как юридического понятия. Обоснованием самой возможности и необходимости разработки вопроса 
о дисфункции права с позиций общей теории права выступает онтологическая связь между правом и последствиями его функционирования в общественных отношениях, которая дает основания констатировать:

1) наличие связи функции права как внутренне присущего ему свойства оказывать воздействие, соответствующее социальному назначению права и самого функционального воздействия;

2) наличие в общественных отношениях последствий, как функционального воздействия права, так и воздействия не соответствующего социальному назначению права и поэтому не являющегося функциональным, а дисфункциональными;

3) наличие связи между дисфункциональными последствиями воздействия права на общественные отношения и источником такого воздействия в самом праве - дисфункцией права.

При исследовании дисфункции права с позиций юридического функционализма должен быть учтен как опыт непосредственного внедрения социологического понятия исследования в теории права, так и положения социологии о функциях и дисфункциях социальных институтов. Использование определенной методологии вовсе не исключает обращения к элементам других. Однако это не должно сводиться к механическому переносу готовых теоретических конструкций, готовых понятий, встроенных в иной исследовательский контекст, так как сходство терминологии не всегда подразумевает сходство понятий ею обозначаемых. В случае, когда определенная идея, переосмысленная и развернутая в ту или иную форму научного знания, способна дать положительный познавательный эффект, отказ от ее использования не обоснован. Однако это использование должно быть рациональным, согласованным с элементами метода теории права. С учетом этого, воспринимая социологическую концептуальную схему взаимосвязи дисфункции и функции, нужно идти от дисфункции в социологическом понимании как последствий воздействия права на общественную систему к дисфункции права как к источнику дисфункционального воздействия самом праве отражаемому уже в правовом понятии.

Если функция права под определенным углом зрения выступает «точкой сборки» активности права соответствующей его социальному назначению, то в таком же ключе должна быть интерпретирована и дисфункция права, другое дело что она «собирает» и направляет энергию отличную от функциональной. Понятие дисфункции должно быть наполнено юридическим содержанием и быть соотносимым именно с понятием функции права. Разработка дисфункции права как правового понятия предполагает не просто терминологические новации, а полноценные исследования связей, зависимостей и отношений в самом праве, приводящих к самой возможности оказания им воздействия, не соответствующего его социальному назначению.

Разработка понятия дисфункции права, в свою очередь, даст толчок новому этапу функционального анализа права. Исследование дисфункций права является перспективным для обнаружения и изучения как самих этих очагов нефункциональной активности, так и того, что создает потенциал такой активности в праве. Для этого на основе переосмысления, адаптации к предмету теории права и в результате согласования их с понятийно-категориальным аппаратом теории функций права вполне могут быть востребованы и другие положения социологического функционализма. Перспективными видятся идеи Р. Мертона: о балансе функциональных последствий [10, с. 394], на основе которой может быть разработана методика анализа оценки эффективности функций права и анализа процесса функционирования; о явных и латентных функциях [10, с. 414], способная трансформироваться в теории права в понятия явных и латентных функциональных и дисфункциональных последствий, востребованных при исследовании правотворчества, а также в правотворческой деятельности в процессах правотворческого анализа, моделирования и прогнозирования. Здесь же вполне может быть использована идея о функциональных альтернативах, эквивалентах [9, с. 123] и др.

При этом особо подчеркнем, что исследование дисфункциональной проблематики в праве предполагает не перенесение понятий социологии, а творческую их адаптацию к предмету и методу юридической науки, их гармонизацию с уже сложившимся в ней понятийнокатегориальным аппаратом. Теория права должна брать не готовый продукт, а концептуальные схемы, идеи, отражающие зависимости между явлениями, выявленные социологией, выступающие ориентиром для анализа схожих 
зависимостей и связей в самом праве и на этой основе разрабатывать собственное понятие.

Таким образом, опыт функционального исследования права на основе переноса социологического понятия дисфункции в теорию права не предоставляет достаточных свидетельств эффективности и продуктивности использования социологически интерпретированного понятия дисфункции (правовая дисфункция, дисфункция права). Это вызывает сомнения в его способности обеспечить качественный прирост научного знания о праве, и делает его применение в таком виде нецелесообразным. Продуктивное использование понятия дисфункции в теории права, возможно лишь на основе восприятия самой идеи дисфункции, причем соотносимой с функцией, при условии ее творческой адаптации к предметно-методологической специфике юридической науки, обеспечивающей ее органичное вхождение в понятийно-категориальные ряды общей теории права в результате разработки понятия дисфункции права как правового понятия.

\section{Библиографический список}

1. Алексеев С. С. Общая теория права. Курс в 2-х т. Т. 1. М.: Юрид. лит., 1981.360 с.

2. Бирюков С.В. О понятии и видах функций права // Омские научные чтения - 2018. Материалы Второй Всероссийской научной конференции. Редколлегия: Т.Ф. Ящук [и др.]. Омск: Омский государственный университет им. Ф.М. Достоевского. 2018. С. 1054-1056.

3. Дамирли М.А. Правовая дисфункция: понятие, вид, проявления, причины и пути преодоления. // Вестн. Волгогр. гос. ун-та. Сер. 5, Юриспруд. 2013. № 2 (19). С. 14-17.

4. Жимиров В.Н. Юридический функционализм (теоретико-методологический анализ). Автореф. дис. ... докт. юрид. наук. С.-Пб., 2005. 40 с.

5. Карташов, В.Н. Теория правовой системы общества: учебное пособие. В 2 т. Т. I; Ярославль: ЯрГУ, 2005. 547 c.

6. Комарова Я.Б. Правовая дисфункция: к постановке проблемы // Синергия Наук. 2018. № 28. С. 798-803.

7. Лановая Г.М. Функциональная характеристика права гражданского общества // Вестник Московского университета МВД России. 2017. № 3. С. 79-82.

8. Малько А.В. Правовая система и правовая жизнь общества // Журнал российского права. 2014. № 7. С 51-60.

9. Мертон Р. Социальная теория и социальная структура. М.: АСТ: АСТ МОСКВА: ХРАНИТЕЛЬ. 2006. 873 с.

10. Мертон Р. Явные и латентные функции // Американская социологическая мысль: Тексты: [Перевод] / Сост. Е.И. Кравченко; Под ред. В.И. Добренькова. М.: Изд-во МГУ, 1994. С. 379-448.

11. Осипян Б.А. Принцип функциональной целесообразности закона // Законодательство и экономика. 2009. № 2. С. 60-68.

12. Палазян А.С. Принципы систематизации функций права // Юридический мир. 2009. № 2 (146). С. 51-54.

13. Плотников В.В. Деструкция и дисфункция социальных институтов: анализ жизнеспособности государственной системы // Теория и практика общественного развития. 2014. № 21. С. 44-46;

14. Радько Т.Н. Теория функций права. М.: Проспект, 2014.272 с.

15. Торопов, А.А. Восстановительная функция права: Вопросы теории и практики: Автореф. дис. ... канд. юрид. наук. Н. Новгород. 1998.25 с. 